Hydrology and Earth System Sciences, 5(1), 93-102 (2001) @

\title{
Regional analysis using the Geomorphoclimatic Instantaneous Unit Hydrograph
}

\author{
M.J. Hall ${ }^{1}$, A.F. Zaki² and M.M.A. Shahin ${ }^{1}$ \\ ${ }^{1}$ International Institute for Infrastructural, Hydraulic and Environmental Engineering, PO Box 3015, 2601 DA Delft, The Netherlands \\ ${ }^{2}$ Water Resources Research Institute, National Water Research Centre, El-Qanater El-Khairyya, Egypt 13621 \\ Email for corresponding author: mjh@ihe.nl
}

\begin{abstract}
The construction of design flood hydrographs for ungauged drainage areas has traditionally been approached by regionalisation, i.e. the transfer of information from the gauged to the ungauged catchments in a region. Such approaches invariably depend upon the use of multiple linear regression analysis to relate unit hydrograph parameters to catchment characteristics and generalised rainfall statistics. The concept of the geomorphological instantaneous unit hydrograph (GIUH), in relating the shape and scale of the catchment transfer function to stream network topology and channel characteristics, offers an alternative methodology. GIUH derivation depends upon a series of assumptions, including that of estimating a "characteristic velocity"; these continue to attract attention and debate. However, if this velocity is expressed in terms of the kinematic wave approximation, the peak and time-to-peak of the IUH may be expressed in terms of a group of catchment and channel characteristics and the intensity of rainfall excess, giving the so-called geomorphoclimatic IUH (GCIUH). Previous studies involving the GCIUH have developed a single IUH relating to the total duration of rainfall excess. In this study, the rainfall excess duration was divided into several (equal) time increments, with separate IUHs being generated for each interval. This quasi-linear approach was applied to 105 storm events from nine catchments in the south-west of England, ranging in size from 6 to $420(\mathrm{~km})^{2}$. The results showed that, providing the time interval chosen is fine enough to capture the shape of the runoff hydrographs, a comparable level of goodness-of-fit can be obtained for catchments covering a range of about 1:75 in area. The modified GCIUH approach as described is therefore recommended for further investigation and intercomparison with regression-based regionalisation methods.
\end{abstract}

Keywords: floods; geomorphology; rainfall-runoff modelling

\section{Introduction}

There can be few, if any, practising engineering hydrologists who have not been called upon to produce estimates of the magnitude of the flood corresponding to a specified return period for a catchment without a conveniently-located gauging station. The problem is compounded if the hydrograph of the flood is required in addition to the peak flow rate. Various techniques of regionalisation, i.e. the transfer of information from the gauged to the ungauged sites in a region, have been developed specifically for this purpose. In general, relationships are sought between the magnitude of key parameters, such as the time-to-peak of the instantaneous unit hydrograph (IUH), and a selection of catchment characteristics, which can be measured from a topographic map, and generalised rainfall statistics, such as average annual rainfall. The preferred technique for developing such relationships has invariably been multiple linear regression analysis (MLRA), although the potential for applying modern informatic tools, such as artificial neural networks, has recently been demonstrated, at least for constructing regional flood frequency distributions (see Hall and Minns, 1999). Many national flood estimation procedures, such as the UK Flood Studies Report (FSR) (Natural Environment Research Council, 1975), have successfully applied MLRA to develop relationships for key parameters, but levels of explained variance are not always as high as could be wished.

When constructing an IUH, its shape is often approximated by a simple geometric figure, such as a triangle, as in the FSR procedure and that developed by the US Soil Conservation Service (see McCuen, 1982). Alternatively, a simple conceptual hydrological model is invoked, such as a cascade of linear reservoirs (e.g. Nash, 1960). Descriptors 
of the geometrical figure, or the parameters of the conceptual model, then form the dependent variables in the MLRA. The choice of independent variables is often limited to information that is either readily available or easily measured, and so may not reflect any theoretical link between the hydrology and the geomorphology of the catchments in the region. The concept of the geomorphological instantaneous unit hydrograph (GIUH), introduced by Rodriguez-Iturbe and Valdes (1979), has provided the basis for such a link, but has attracted comparatively little attention as a potential practical tool for the regionalisation of catchment response.

Although the GIUH can be formulated on a deterministic basis (see Chutha and Dooge, 1990), the original papers were cast in a probabilistic framework. As restated by Gupta et al. (1980), the IUH is interpreted as a probability density function (PDF) of water travel times within a catchment. The scale and shape of the GIUH then depend upon assumptions on

(a) the probability that a droplet of rain will fall on to an area draining to a stream of order, $i$;

(b) the transition probability of the droplet from the stream of order $i$ to that of order $j, i £ j$; and

(c) the probability density function (PDF) selected to describe the holding times for any given order of stream.

Items (a) and (b) are independent of scale and determined only by network topology, which can be described in terms of the Horton ratios. In contrast, the holding times are dependent upon the drainage channels and their hydraulic properties. For intensities of rainfall excess which are essentially constant within their duration, the GIUH approach allows explicit equations to be developed for the peak rate of flow and the time-to-peak of the direct runoff hydrograph in terms of catchment and channel characteristics. No calibration with observed rainfall and flow data is required. However, the derivation of these equations involves a series of assumptions that are required essentially to maintain the tractability of the method and to minimise the amount of map (and field) work.

In this paper, the GIUH approach is applied to data from a group of catchments in the south-west of England varying in size from just under 6 to $422 \mathrm{~km}^{2}$. A selection of storm events was analysed for each catchment in order to determine whether comparable levels of goodness-of-fit can be obtained, thereby demonstrating the utility of the GIUH catchment and channel characteristics as a possible basis for the regionalisation of catchment response. The paper begins with a brief overview of the concept, emphasising the several practical issues that are encountered in its application. In particular, a variant of an extended version of the original GIUH approach, the so-called geomorphoclimatic instantaneous unit hydrograph or GCIUH (see RodriguezIturbe et al., 1982), is proposed that permits the analysis of storms with variable rates of rainfall excess. The data employed in the study, which were obtained from the Representative Basin Catalogue for Great Britain maintained by the Centre for Ecology and Hydrology, Wallingford, are then described, prior to the presentation of results and some concluding remarks.

\section{The Geomorphoclimatic Instantaneous Unit Hydrograph}

Comprehensive descriptions of the derivation of the GIUH, and its extension to the GCIUH, have already been provided by Gupta et al. (1980); Bras and Rodriguez-Iturbe (1989) and Bras (1990; Ch 12). As noted above, the IUH of a catchment, $h(t)$, can be interpreted as the PDF of the water travel times within the catchment, i.e.

$$
h(t)=\sum_{\text {all }} f_{\text {paths }}(t) \cdot P(s)
$$

where $f_{T s}(t)$ is the PDF of total path travel times within the catchment and $P(s)$ is the probability that a water droplet will follow the specific path, $s$. The latter depends upon the product of the probability that a droplet will originate from a hillslope segment draining to a stream of a particular order, and the transition probabilities of moving between different orders of streams within the network. These probabilities can be evaluated exactly for any specific drainage area (see Rodriguez-Iturbe and Valdes, 1979; Gupta et al., 1980). However, a form of PDF must be assumed for the distribution of total path travel times, and Rodriguez-Iturbe and Valdes (1979) proposed the exponential

$$
f_{T s}(t)=K_{i} \quad \exp \left(-K_{i} t\right)
$$

where $K_{i}^{-1}$ is the mean travel time in channels of order $i$, and can be approximated by

$$
K_{i}=\frac{U}{\bar{L}_{i}}
$$

where $U$ is a "characteristic velocity", assumed constant throughout the network, and $L_{i}$ is the average length of streams of order $i$. Selection of the most appropriate value of $U$ has proved to be one of the most widely-debated aspects of the GIUH approach. Suggested values include the average flow velocity (Rodriguez-Iturbe and Valdes, 1979), the 
velocity at the instant of peak discharge (Rodriguez-Iturbe et al., 1979) and the velocity of the flood wave (Kirshen and Bras, 1983). More recently, Franchini and O’Connell (1996) have proposed that this velocity should be considered purely as a calibration parameter. Those authors proceeded to develop a prediction equation for $U$ in terms of the Horton length ratio and the length of the highest-order stream of the catchment, along with a time of concentration derived from the time base of the IUH. Similarly, Al-Wagdany and Rao (1997) have related the characteristic velocity to the total rainfall depth, the total catchment area and a cumulative slope parameter. Of course, $U$ may be related to the discharge, $Q$, by the familiar power function

$$
U=K_{1} \quad Q^{a}
$$

where $K_{1}$ is a constant and $a$ is the power. According to Pilgrim (1977; Table 1), $0.05 £$ a $£ 0.19$. Over this range, a doubling of discharge results in a change in $U$ of only between 4 and 14 per cent. This comparative lack of sensitivity may well account for the variety of the definitions that have been suggested.

Leaving aside for the moment the problem of defining $U$, even with the assumption of an exponential distribution for the PDF of total path travel times, Eqn. (1) is tedious to evaluate for specific catchments. Rodriguez-Iturbe and Valdes (1979) therefore proposed a simplified procedure based upon two assumptions. Firstly, the shape of the IUH was taken to be triangular and, therefore fully specified by its peak, $q_{p}\left(h^{-1}\right)$, time-to-peak, $t_{p}(h)$ and time base, $t_{b}(h)$; and secondly, the rate of rainfall excess, $i_{r}$, was essentially constant throughout its duration, $t_{r}(h)$. Under these conditions, following Henderson (1963), the peak discharge, $Q_{p}$, and the time-to-peak, $T_{p}$, of the resultant direct runoff hydrograph may be expressed as

$$
\begin{aligned}
& Q_{p}=Q_{e} \frac{2 t_{r}}{t_{b}}\left(1-\frac{t_{r}}{2 t_{b}}\right) \\
& T_{p}=t_{p}+t_{r} \quad\left(1-\frac{q_{p} t_{p}}{2}\right)
\end{aligned}
$$

where $Q_{e}$ is the equilibrium discharge given by the product of $i_{r}$ and the catchment area. The variable, $t_{b}$, can be eliminated from Eqn. (5), which applies for all $t_{r} £ t_{b}$, by noting that, for a triangular IUH, $q_{p} \cdot t_{b}=2$ :

$$
Q_{p}=Q_{e} \quad q_{p} \quad t_{r}\left(1-\frac{q_{p} t_{r}}{4}\right)
$$

To estimate $q_{p}$ and $t_{p}$, Rodriguez-Iturbe and Valdes (1979) developed analytical solutions to a wide range of cases of network geometry using Eqn. (1), and then regressed the values obtained on the characteristics of the networks analysed. The results were:

$$
\begin{gathered}
q_{p}=\frac{1.31}{L_{\Omega}} R_{L}^{0.43} \quad U \\
t_{p}=\frac{0.44 L_{\Omega}}{U}\left(\frac{R_{B}}{R_{A}}\right)^{0.55} R_{L}^{-0.38}
\end{gathered}
$$

where $R_{A}, R_{B}$ and $R_{L}$ are the Horton area, bifurcation and length ratios of the catchment, $L_{S}$ is the length $(\mathrm{km})$ of the highest order stream and $U$ is the average peak flow velocity $\left(\mathrm{m} \mathrm{s}^{-1}\right)$. Since Eqns. (8) express the dependent variables in terms of catchment characteristics and a velocity term which can be estimated from the properties of the cross section at the catchment outlet, the IUH can be synthesised without the need for calibration with observed rainfall and flow records. Therein lies the advantage of this approach. However, Rodriguez-Iturbe and Valdes (1979) remained concerned about the extent of the geomorphological analysis required to determine $R_{A}, R_{B}$ and $R_{L}$, and proposed that $R_{B} / R_{A}$ should be set at a constant value of 0.8 , thereby leaving only three independent variables, $R_{L}, L_{S}$ and $U$, to be estimated.

Equations (8) constitute the basis of the GIUH. In a later contribution, Rodriguez-Iturbe et al. (1982) proposed a more rigorous approach for determining the characteristic velocity term, $U$, by applying the kinematic wave assumptions. Provided that the duration of rainfall excess exceeds the time to equilibrium for the first-order basins in a catchment, the equilibrium discharge, $Q_{1}$, for those basins is given by the product of $i_{r}$ and their average area, $A_{1}$. Given that the mean flow velocity, $U_{1}=Q_{1} / A$, where $A$ is the cross-sectional area of the channel, and noting that

$$
Q_{1}=\alpha_{c} \quad A^{m}
$$

where $a_{c}$ is the kinematic wave parameter of the channel, $A$ can be eliminated to give

$$
U_{1}=\frac{Q_{1}}{A}=Q_{1} \quad\left(\frac{\alpha_{c}}{Q_{1}}\right)^{\frac{1}{m}}=\alpha_{c}^{\frac{1}{m}} \quad\left(i_{r} \quad A_{1}\right)^{\frac{m-1}{m}}
$$

However, the area ratio, $R_{A}$, can be invoked along with the assumption that

$$
U_{1}=U_{\Omega} ; \quad Q_{1}=i_{r} \quad A_{1} ; \quad Q=i_{r} \quad A_{\Omega}
$$

where the subscript, $S$, refers to the highest-order basin in 
the catchment, to give

$$
A_{1}=A_{\Omega} \quad R_{A}^{1-\Omega} ; \alpha_{1}=\alpha_{\Omega} \quad\left(R_{A}^{\Omega-1}\right)^{m-1}
$$

With the further assumption that $m=5 / 3$, Eqn. (10) may be expanded into

$$
U=0.665 \quad \alpha_{\Omega}^{0.6}\left(i_{r} \quad A_{\Omega}\right)^{0.4}
$$

where $U$ is in $\mathrm{m} \mathrm{s}^{-1}, \mathrm{a}_{\mathrm{S}}$ is in $\mathrm{m}^{-1} \cdot \mathrm{s}^{-1 / 3}, i_{r}$ is in $\mathrm{cm} \mathrm{h}^{-1}$ and $A_{S}$ is in $\mathrm{km}^{2}$. Assuming $R_{B} / R_{A}=0.8$ and that $R_{L}$ is raised to the power 0.4 in both expressions, Eq (13) may be substituted into Eqns. (8) to give new relations for $q_{p}$ and $t_{p}$ :

$$
q_{p}=\frac{0.871}{\Pi^{0.4}} ; \quad t_{p}=0.585 \Pi^{0.4}
$$

where

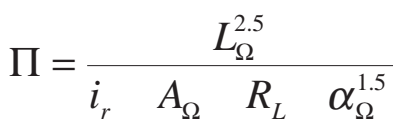

and the kinematic wave parameter of the highest-order stream, $a_{W}$, is obtained from Eqn. (9) by invoking the Manning uniform flow formula, expressing $A$ as the product of breadth, $B_{W}$, and depth, $h$, of flow in the highest-order stream:

$$
Q=\alpha_{\Omega} \quad A^{m}=\frac{A}{n} \quad h^{\frac{2}{3}} \quad \sqrt{S_{\Omega}}
$$

hence

$$
\alpha_{\Omega}=\frac{B_{\Omega} h}{B_{\Omega}^{m} h^{m} n} h^{\frac{2}{3}} \quad \sqrt{S_{\Omega}}=\frac{h^{\frac{2}{3}}}{\left(B_{\Omega} h\right)^{m-1} n} \sqrt{S_{\Omega}}
$$

where $S_{W}$ is the slope and $n$ the Manning roughness coefficient of the highest-order stream. Since $m=5 / 3$ for Manning roughness,

$$
\alpha_{\Omega}=\frac{\sqrt{S_{\Omega}}}{n B_{\Omega}^{\frac{2}{3}}}
$$

and Eqn. (15) may be revised as

$$
\Pi=\frac{n^{\frac{3}{2}} L_{\Omega}^{\frac{5}{2}} B_{\Omega}}{i_{r} \quad A_{\Omega} \quad R_{L} \quad S_{\Omega}^{\frac{3}{4}}}
$$

Using this value of P, Eqns. (14) may be substituted into Eqns. (7) and (6) to give the peak $\left(\mathrm{m}^{3} \mathrm{~s}^{-1}\right)$ and the time-topeak $(h)$ respectively of the direct runoff hydrograph for a constant intensity, $i_{r}$, of rainfall excess over the duration, $t_{r}$ :

$$
\begin{aligned}
& Q_{p}=2.42 \frac{i_{r} A_{\Omega} t_{r}}{\Pi^{0.4}}\left(1-\frac{0.218 t_{r}}{\Pi^{0.4}}\right) \\
& T_{p}=0.585 \Pi^{0.4}+0.745 t_{r}
\end{aligned}
$$

Since Eqns. (14) depend only on geomorphological and climatic data, they are referred to as the geomorphoclimatic IUH or GCIUH. Note, however, that the relationship between rainfall excess and direct runoff is now only quasi-linear, i.e. the linear operation is only valid once $i_{r}$, which features prominently in the $\mathrm{P}$-term, and $t_{r}$ have been determined.

In practice, the condition that the intensity of rainfall excess is reasonably constant throughout $t$ is unduly restrictive. However, for storms in which $i_{r}$ varies markedly in time, the total duration may be conveniently divided into a series of increments, $D t$, and a different GCIUH associated with each increment according to the average intensity of rainfall excess in each successive interval. The drawback to this approach is the possibility that the chosen $D t$ may not satisfy the assumption associated with the application of the kinematic wave approximation that the duration of rainfall excess exceeds the equilibrium time for the first-order basins. In these circumstances, the second and third identities of Eqns. (11) are no longer applicable. If $D t$ does not exceed the time to equilibrium when applying the kinematic wave approximation, then Eqn. (13) may be revised into (see Nowicka and Soczynska, 1989):

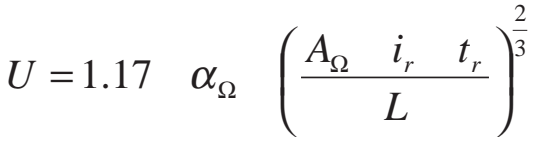

where $L$ is the main channel length of the catchment. Using the same units and assumptions as before, Eqns. (14) become:

$$
q_{p}=\frac{1.533}{\Pi_{1}^{\frac{2}{3}}} ; \quad t_{p}=0.333 \Pi_{1}^{\frac{2}{3}}
$$

where

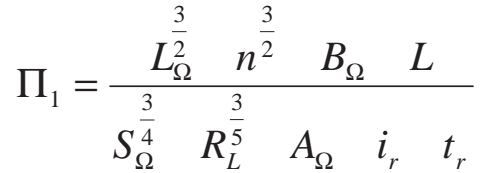

Since in this study the total duration of rainfall was divided into a series of successive increments of $D t$, Eqns. (22) and 
(23) were used to define the form of the IUH in preference to Eqns. (14) and (18).

\section{The data}

To evaluate the ability of Eqns. (22) to describe a transfer function that can be applied over a wide range of catchment sizes, rainfall and runoff data were obtained from the Representative Basin Catalogue for Great Britain maintained by the Centre for Ecology and Hydrology, Wallingford, UK. A total of nine catchments was selected from the south-west of England, covering almost two orders of magnitude of drainage area. Further details of the catchments are summarised in Table 1, along with the numbers of storm events for each site which were analysed. The data were obtained in ASCII file format, with runoff hydrographs $\left(\mathrm{m}^{3} \mathrm{~s}^{-}\right.$ ${ }^{1}$ ) listed at one-hour (but in some cases 30-minute) intervals, and rainfall hyetographs in the form of areally-averaged totals $(\mathrm{mm})$ at one-hour intervals. The areal averaging had been performed using the Autostorm method. In this approach, individual raingauge totals are multiplied by a weight, defined as the ratio of the reciprocal of the distance between the raingauge site and the centre of the catchment divided by the sum of the reciprocals for all the raingauges used. The products are then summed to give a total for each time unit (see Natural Environment Research Council, 1975; Figure 6.5).

Equations (22) incorporate the length ratio of the catchment, $R_{L}$, and implicit in their derivation is the assumption that the ratio of the bifurcation ratio, $R_{B}$, to the area ratio, $R_{A}$, is approximately 0.8 . These ratios are defined as follows:

$$
R_{A}=\frac{A_{\omega-1}}{A_{\omega}} ; \quad R_{B}=\frac{N_{\omega-1}}{N_{\omega}} ; \quad R_{L}=\frac{L_{\omega-1}}{L_{\omega}}
$$

where $A_{T}, N_{T}$ and $L_{T}$ are the average area draining, the number and the average length of the $w$-order streams respectively. Since the preferred 1:25,000 scale Ordnance Survey maps could not be obtained within the time scale of this study, estimates of the ratios were derived from 1:50,000 maps from the Landranger series. Values of the ratio, $R_{B} / R_{A}$ were found to range from 0.685 to 0.987 with a mean of 0.822 . Using Eqns. (8) for $t_{p}$, this variation would cause changes in the time-to-peak between +7 and -12 per cent, which for this study was deemed acceptable. Length ratios varied from 2.48 (Pixton) to 1.4 (Tinhay).

In addition to the total catchment area, $A_{\mathrm{w}}$, its main channel length, $L$, and the length ratio, $R_{L}$. Equation (23) requires additional information that relates essentially to the highestorder stream, including its length, $L_{W}$, slope, $S_{W}$, and Manning roughness coefficient, $n$, and the breadth, $B_{W}$, of the outlet cross-section. The first two parameters were estimated from the 1:50,000 maps and the Manning roughness coefficient was extracted from standard tabulations, based upon the station descriptions contained in the Hydrological Data UK Yearbooks (e.g. Institute of Hydrology and British Geological Survey, 1989). Strictly, since the velocity, $U$, is supposedly a peak flow velocity, $B_{W}$ should be the width of the crosssection associated with the peak discharge of the event. However, since the time available precluded site visits, and in the absence of detailed cross-sectional information, a relationship was developed between bankfull widths and bankfull discharges, $Q_{B}\left(\mathrm{~m}^{3} \mathrm{~s}^{-1}\right)$, for the stations identified in Table 1 and others in the same hydrometric regions using data from the Representative Basin Catalogue and the Yearbooks. A linear regression using the logarithms of the variables yielded the expression

$$
B_{\Omega}=\exp \left(0.7+0.468 \ln Q_{B}\right)
$$

Table 1. Details of catchment areas for which data were analysed

\begin{tabular}{llcc}
\hline Station no & Catchment & Area $(\mathrm{km})^{2}$ & No of events \\
\hline 45002 & Exe at Stoodleigh & 421.7 & 10 \\
45009 & Exe at Pixton & 147.6 & 18 \\
46003 & Dart at Austins Bridge & 247.6 & 13 \\
46005 & East Dart at Bellever & 21.5 & 15 \\
46802 & Swincombe at Swincombe Intake & 14.2 & 11 \\
46805 & Bala Brook & 5.67 & 5 \\
47007 & Yealm at Puslinch & 54.9 & 10 \\
47008 & Thrushel at Tinhay & 112.7 & 11 \\
47011 & Plym at Carn Wood & 79.2 & 12 \\
\hline
\end{tabular}


with an explained variance of 87 per cent. Equation (25) was then applied to approximate $B_{W}$ for each event.

\section{Data analysis}

The GCIUH is defined in the same manner as any instantaneous unit hydrograph in terms of a transfer function between rainfall excess and direct runoff. The testing of the technique therefore required the prior separation of the baseflow component from the observed hydrographs and the determination of the rainfall excess from the hyetograph of areal rainfall. Baseflow was assumed to be represented by a straight line joining the start of the rising limb of the hydrograph to the point of inflection on the recession limb. The latter point was identified from the time at which a semilogarithmic plot of the recession became well-represented by a straight line. The losses from the total rainfall were assumed to consist of an initial loss and a continuing loss. The former included all rainfall that occurred prior to the start of the rising limb of the hydrograph. The latter was subtracted as a uniform loss rate determined such that the rainfall excess volume equalled the direct runoff volume obtained by subtracting the baseflow from the observed hydrograph. If the loss rate exceeded the rainfall rate for any time interval, the rainfall excess was set to zero. If the rate of rainfall excess fell below $0.5 \mathrm{~mm} \mathrm{~h}^{-1}$, the rate was also set to zero and the amount equally distributed over the remaining (non-zero rainfall) time intervals. This precaution was taken to avoid the generation of GCIUHs with very low peaks and excessively long time bases that contribute little to the overall shape of the direct runoff hydrograph.

For each of the 105 storm events that were analysed, the rainfall totals for each successive interval of $D t=1$ hour within the distributions of rainfall excess were employed to derive the peak ordinate, $q_{p}$, and time-to-peak, $t_{p}$, of individual GCIUHs using Eqns. (22). The finite-period unit hydrographs were computed using the S-curve technique, and their ordinates proportioned according to the rainfall excess volume within that $D t$. The estimated direct runoff hydrograph was then obtained from the linear superposition of the direct runoff responses for all time intervals within the hyetograph of rainfall excess.

The time interval of one hour was employed in both rainfall and runoff data files, although the discharges for the two smallest catchments (the River Swincombe and Bala Brook - see Table 1) were recorded at 30-minute intervals. As might be anticipated, the responses of these two upland headwater catchments were not well-described at this data interval. Indeed, a time interval of one hour was also rather too long to give satisfactory definition of the hydrographs for the East Dart at Bellever, a neighbouring catchment of a similar flashy character. The following discussion therefore considers the results for the River Swincombe and Bala Brook separately from the other seven.

\section{Discussion of results}

Initially, plots of the computed discharge hydrographs for each storm were compared visually with the original flow data. As an example, Fig. 1 shows the results for six of the ten storms for the River Yealm at Puslinch. This selection includes two of the best results (a,d) and the worst result (e). These data were summarised using two different approaches. Firstly, perhaps the most important characteristics to be replicated by a rainfall-runoff model are the magnitude of the peak flow rate and its timing. Plots were therefore prepared of the computed versus the observed peak flow rates and the estimated versus the measured times-to-peak of all events on the seven largest catchments. These plots are presented in Figs. 2 and 3, which also show lines of equal values. For convenience in presentation, Fig. 2 shows the results for the three largest catchments separately from the others. In Fig. 2(a), the points cluster closely around the line of equal values, whereas, for the two largest catchments in Fig. 2(b), there is a tendency for the model to underestimate observed peak flow rates. With regard to times-to-peak, Fig. 3 again reveals a tendency for the GCIUH technique to underestimate. However, since all data were analysed using a one-hour time interval, the minimum error is one hour and the effect is perhaps exaggerated.

The second approach to summarising the data was based upon the use of an index of the goodness-of-fit for each event. One such index, which has been widely used in hydrological modelling work, is the coefficient of efficiency, $E$, as defined by Nash and Sutcliffe (1970):

$$
E=1-\frac{\sum_{i=1}^{n}\left(Q_{i}-\hat{Q}_{i}\right)^{2}}{\sum_{i=1}^{n}\left(Q_{i}-\bar{Q}\right)^{2}}
$$

where $Q_{i}$ is the observed discharge at time $i, \overline{\mathrm{Q}}$ is the mean of the $Q_{i}$, and $\hat{\mathrm{Q}}_{\mathrm{i}}$ is the computed discharge at time $i$. In Eqn. (26), the sum of the squares of the differences between computed and observed flows is expressed as a proportion of a "no model" variance, i.e. the sum of squares of the deviations when the computed flows are represented by the mean of the observed flows, a null hypothesis that has been criticised by Beran (1999). Subtraction of this ratio from one then provides a coefficient that represents an increasingly better fit as $E$ approaches unity. However, unlike the classical coefficient of determination, its lower limit is minus infinity, 
a

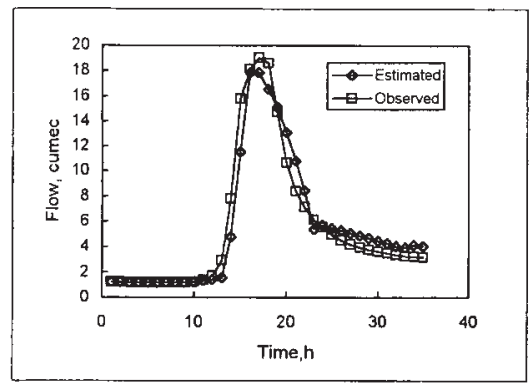

c

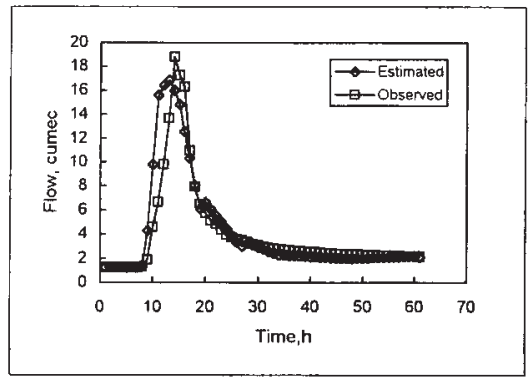

e

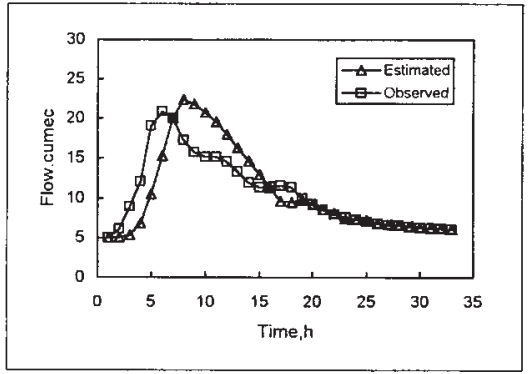

b

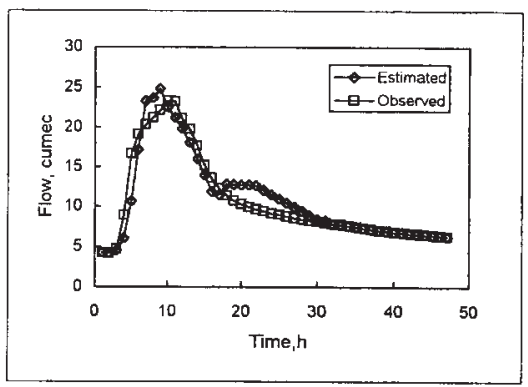

d

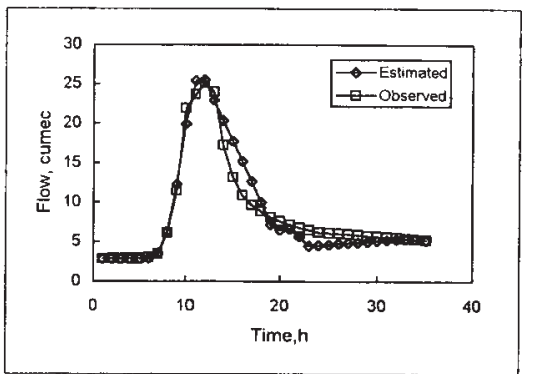

f

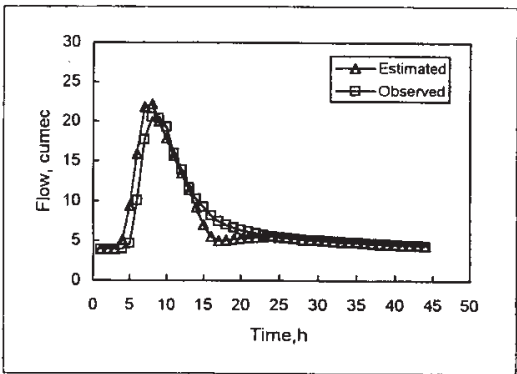

Fig. 1. Observed and estimated hydrographs of storm events for the River Yealm catchment: (a) 24 June, 1968; (b) 27 June, 1968; (c) 10 November, 1965; (d) 28 November, 1965; (e) 24 February, 1966; and (f) 20 February, 1966.

so that poorer levels of performance generate negative numbers. Indeed, of the 105 storms analysed, 61 had negative $E$-values, although only four produced values of -0.5 and below. The value of -0.5 represents the point where the sum of squares of the differences is 50 per cent larger than the variance of the observed data, and for clarity in subsequent presentation, these events have not been considered further. Since $E$ is used here to compare model performance between catchments, its deficiencies as an index of fit were deemed acceptable.

Taking the results from the seven largest catchments, the average, maximum and minimum coefficients of efficiency were obtained as well as their their variation with the size of the catchment area. A plot of these results is presented in Fig. 4, and demonstrates that, for drainage areas of some 50 $\mathrm{km}^{2}$ and over, both average and maximum $E$-values were reasonably consistent. The performance of the method on the largest catchments is quite good, considering the limitations of Eqn. (26), with no $E$-values less than 0.81 and eight of the ten events scoring above 0.9. For the catchments between 50 and $250 \mathrm{~km}^{2}$, the minimum coefficients are also reasonably consistent at around 0.5 . Typically, such values arise from large timing errors; for example, the $E$-value for the storm shown in Fig. 1(e) was 0.54. However, the range of goodness-of-fit for the smallest catchment, the East Dart River, is notably poorer.

For the two smallest catchments, the use of a one-hour time interval proved to be too coarse to capture the details of their response, as has already been noted above. Since the runoff data were available at 30-minute intervals, a further analysis was carried out in which the one-hour rainfall data were divided equally between two successive 30-minute intervals. The $E$-values were greatly improved. A further test was undertaken in which the one-hour rainfall data were divided equally over four successive 15-minute intervals, and 15-minute ordinates were interpolated from the 30minute flow hydrographs. Table 2 summarises the coefficients of efficiency obtained for both catchments. 
(a)

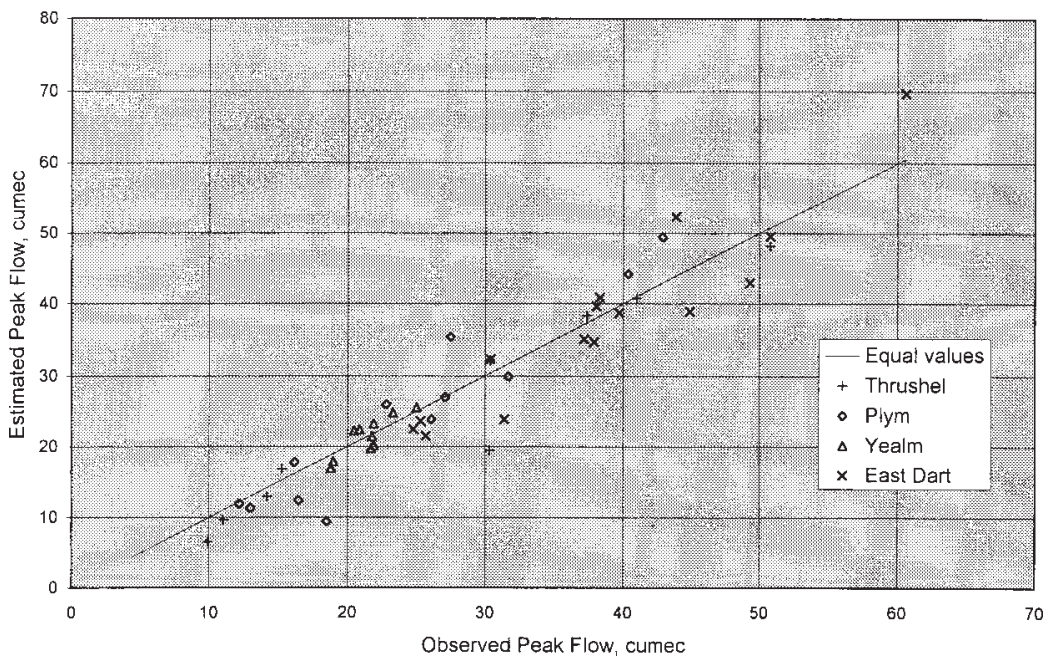

(b)

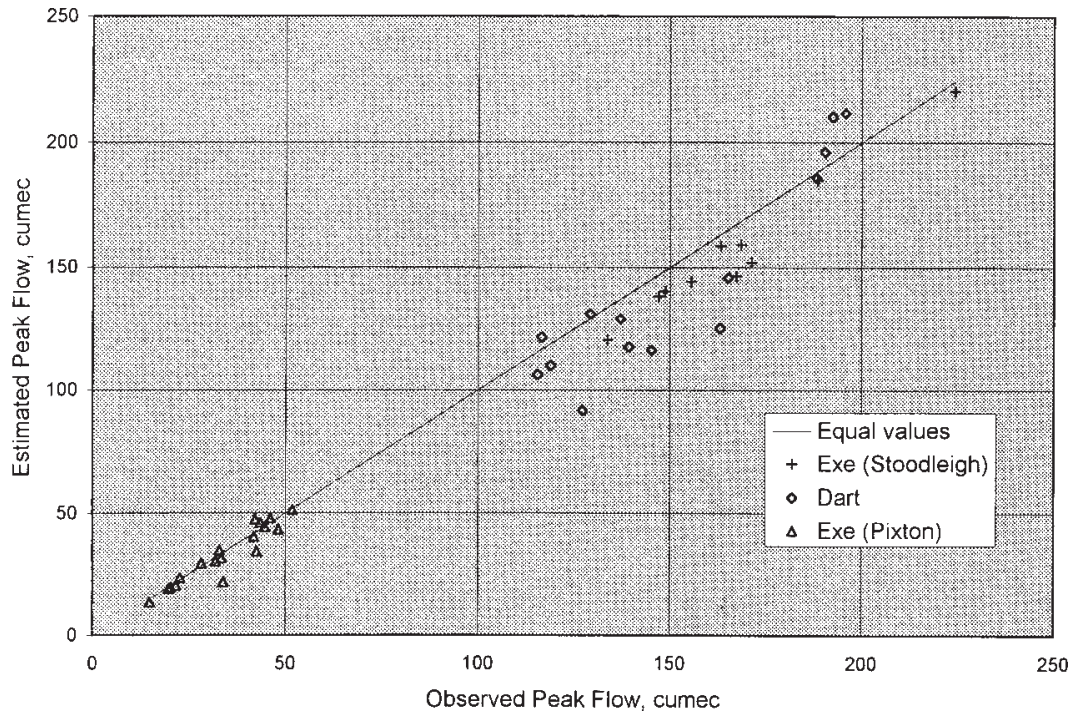

Fig. 2. Estimated versus observed peak flow rates $\left(m^{3} s^{-1}\right)$ along with lines of equal values for (a) catchments less than $120(\mathrm{~km})^{2}$; and (b) catchments larger than $120(\mathrm{~km})^{2}$.

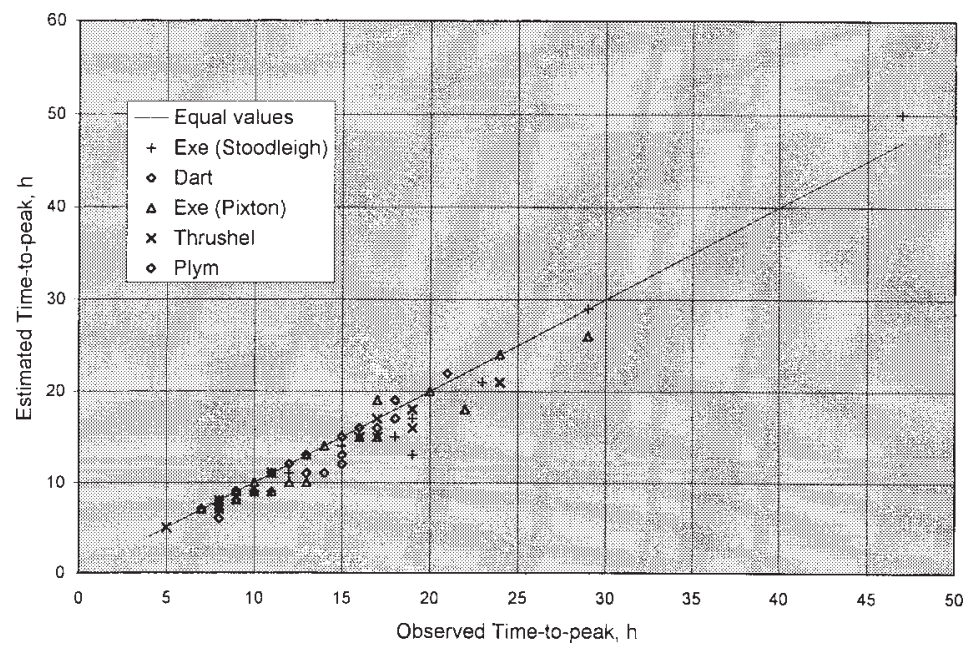

Fig. 3. Estimated versus observed times-to-peak (h) for the seven largest catchment areas (89 events in total). 


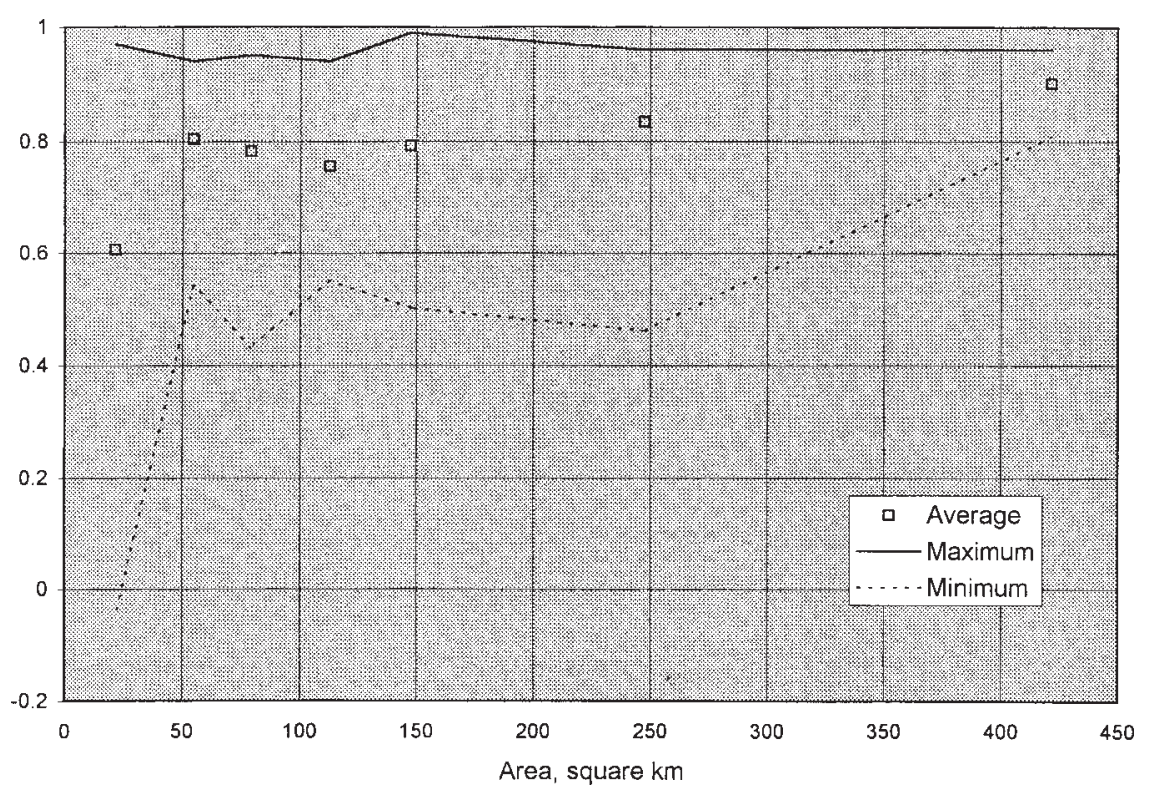

Fig. 4. Average, maximum and minimum values of the coefficients of efficiency for the estimation of storm hydrographs from sets of events for the seven largest catchment areas. Each set contains a minimum of 10 storms (see Table 1).

Table 2. Coefficients of efficiency for storm events on the River Swincombe and Bala Brook using notional 15-minute data

\begin{tabular}{lccc}
\hline \multirow{2}{*}{ Catchment } & \multicolumn{3}{c}{ Coefficients of efficiency } \\
& average & maximum & minimum \\
\hline River Swincombe & 0.81 & 0.96 & 0.30 \\
Bala Brook & 0.80 & 0.97 & 0.63 \\
\hline
\end{tabular}

Table 2 shows that, given data with a sufficiently fine time resolution, the average performance of the GCIUH technique is comparable to that of the seven larger catchments (see Fig. 4). With regard to the minimum $E$-values, that for the River Swincombe is by far the worst; all other events had coefficients above 0.72 . The range of goodness-of-fit for the two smallest drainage areas is therefore somewhat smaller than those of the other catchments, as shown in Fig. 4.

\section{Concluding remarks}

A modification to the basic GCIUH technique has been suggested in which the duration of rainfall excess is divided into a number of equal time increments and IUHs are generated for each time increment rather than for only the total duration. The technique is, as in previous versions of the GCIUH approach, based upon the construction of a triangular shape of IUH whose peak and time-to-peak are expressed in terms of a function, $A_{1}$, given by Eqn. (23). This function involves a set of catchment characteristics, including the total drainage area, the lengths of the main channel and the highest-order stream, the length ratio of the catchment and the breadth, slope and Manning roughness of the highest order stream, all of which can be estimated from maps or from site surveys. The $A_{1}$-term also contains in its denominator the product of the average intensity and the total duration of rainfall excess, so that the peak of the IUH increases and the time-to-peak decreases with increase in the total depth of rainfall excess according to Eqns. (22).

When this approach was applied to the 105 storm events from the nine catchment areas in the south-west of England, Fig. (4) demonstrates that a comparable level of performance was achieved for all six catchments larger than $50 \mathrm{~km}^{2}$. For the three smaller drainage areas, the standard time interval of one hour used in the analysis was found to be too coarse to mirror their flashy behaviour. Numerical experiments with the observed rainfall and flow data showed that when the storm events were analysed with a shorter time interval, a performance comparable to the larger catchments could be expected. This result is reminiscent of the recommended practice in unit hydrograph analysis to choose a data interval that provides at least five points on the rising limb of the direct runoff hydrograph, as for example in the Flood Studies Report procedures (Natural Environment Research Council, 1975). Furthermore, the original basis for deriving the $\mathrm{P}_{1}$-term is that the $D t$ chosen does not exceed the equilibrium 
time for the first-order basins, a condition that a one-hour time interval is unlikely to satisfy on the smaller catchments.

With this proviso relating to the data interval, the $\mathrm{P}_{1}$-term would appear capable of reflecting the essential features of storm events for catchments differing in size by a ratio of 1:75. In terms of sensitivity to the variables entering into the $\mathrm{P}_{1}$-term, the peak and time-to-peak of the IUH are directly proportional to both the length and the Manning roughness of the highest-order stream. Next in order of importance are the breadth of the highest-order stream, the length of the main channel and the area of the total catchment, and the total depth of rainfall excess. A ten per cent change in any of these variables alters $q_{p}$ and $t_{p}$ by some seven per cent. Finally, the slope of the highest-order stream and the length ratio of the catchment produce effects of similar magnitude, with a ten per cent change in either varying the peak and time-topeak by four to five per cent. In effect, the variables derived from maps are of comparable weight to those obtainable by site survey, i.e. the properties of the highest-order stream. As proposed, the approach retains the assumptions relating to the triangular shape of the IUH, the setting of the ratio, $R_{B} / R_{A}$, to a value of 0.8 , and the application of the kinematic wave approximation. Nevertheless, the results obtained would appear to justify a more comprehensive study on a wider range of catchment sizes and types, comparing results with a regionalised approach.

\section{Acknowledgements}

The authors wish to acknowledge the kind cooperation of the Centre for Ecology and Hydrology, Wallingford, in providing the data from the Representative Basin Catalogue for Great Britain that were employed in this study.

\section{References}

Al-Wagdany, A. S. and Rao, A.R., 1997. Estimation of the velocity parameter of the geomorphologic instantaneous unit hydrograph, Water Resour. Mgmt., 11, 1-16.
Beran, M., 1999. Hydrograph prediction - how much skill? Hydrol. Earth System Sci., 3, 305-307.

Bras, R.L., 1990. Hydrology. An introduction to hydrologic science, Addison-Wesley, Reading, Mass, 643 pp.

Bras, R.L. and Rodriguez-Iturbe, I., 1989. A review of the search for a quantitative link between hydrologic response and fluvial geomorphology. In: New Directions for Surface Water Modelling, M.L. Kavvas, (Ed.), Proc. Baltimore Symp., Inter. Assoc. Hydrol. Sci. Pubn. No. 181, 149-163.

Chutha, P., and Dooge, J.C.I., 1990. The shape parameters of the geomorphologic unit hydrograph, J. Hydrol., 117, 81-97.

Franchini, M. and O'Connell, P.E., 1996. An analysis of the dynamic component of the geomorphologic instantaneous unit hydrograph, J. Hydrol., 175, 407-428.

Gupta, V. K., Waymire, E. and Wang, C. T., 1980. Representation of an instantaneous unit hydrograph from geomorphology, Water Resour. Res., 16, 855-862.

Hall, M.J. and Minns, A.W., 1999. The classification of hydrologically homogeneous regions, Hydrol. Sci. J., 44, 693-704.

Henderson, F.M., 1963. Some properties of the unit hydrograph, $J$. Geophys. Res., 68, 4785-4793.

Institute of Hydrology and British Geological Survey, 1989. Hydrological data UK 1988 yearbook, Natural Environment Research Council, Wallingford, 192pp.

Kirshen, D.M. and Bras, R.L., 1983. The linear channel and its effect on the geomorphologic IUH, J. Hydrol., 65, 175-208.

McCuen, R.H., 1982. A guide to hydrologic analysis using SCS methods, Prentice-Hall Inc, Englewood Cliffs, NJ, 145 pp.

Nash, J.E., 1960. A unit hydrograph study with particular reference to British catchments, Proc. Inst. Civil. Eng., 17, 249-282.

Nash, J.E. and Sutcliffe, J.V., 1970. River flow forecasting through conceptual models, J. Hydrol., 10, 282-290.

Natural Environment Research Council, 1975. Flood Studies Report, Vol I: Hydrological Studies, NERC, London, 550 pp.

Nowicka, B. and Soczynska, U., 1989. Application of GIUH and dimensionless hydrograph models in ungauged basins, In: FRIENDS in Hydrology, L. Roald, K. Nordseth and K.A. Hassel (Eds), Proc. Bolkesjø Symp., Inter.. Assoc. Hydrol. Sci. Pubn. 187, 197-203.

Pilgrim, D.H., 1977. Isochrones of travel time and distribution of flood storage from a tracer study on a small watershed, Water Resour. Res., 13, 587-595.

Rodriguez-Iturbe, I. and Valdes, J.B., 1979. The geomorphologic structure of hydrologic response, Water Resour. Res., 15. 14091420 .

Rodriguez-Iturbe, I., Devoto, G. and Valdes, J.B., 1979. Discharge response analysis and hydrological similarity, Water Resour. Res., 15, 1435-1444.

Rodriguez-Iturbe, I., Gonzalez-Sanabria, M. and Bras, R.L., 1982. A geomorphoclimatic theory of the instantaneous unit hydrograph, Water Resour. Res., 18, 877-886. 